University of Nebraska - Lincoln

DigitalCommons@University of Nebraska - Lincoln

Faculty Publications: Department of

Entomology

Entomology, Department of

2005

\title{
Multiple Transatlantic Introductions of the Western Corn Rootworm
}

Nicholas Miller

University of Nebraska-Lincoln, nmiller11@iit.edu

Arnaud Estoup

Centre de Biologie et de Gestion des Populations

Stefan Toepfer

CABI Bioscience, Switzerland Centre Field Laboratories

Denis Bourguet

Centre de Biologie et de Gestion des Populations

Laurent Lapchin

Institute National de la Recherche Agronomique (INRA)-Université de Nice

See next page for additional authors

Follow this and additional works at: https://digitalcommons.unl.edu/entomologyfacpub

Part of the Entomology Commons

Miller, Nicholas; Estoup, Arnaud; Toepfer, Stefan; Bourguet, Denis; Lapchin, Laurent; Derridj, Sylvie; Kim, Kyung Seok; Reynaud, Philippe; Furlan, Lorenzo; and Guillemaud, Thomas, "Multiple Transatlantic Introductions of the Western Corn Rootworm" (2005). Faculty Publications: Department of Entomology. 250.

https://digitalcommons.unl.edu/entomologyfacpub/250

This Article is brought to you for free and open access by the Entomology, Department of at DigitalCommons@University of Nebraska - Lincoln. It has been accepted for inclusion in Faculty Publications: Department of Entomology by an authorized administrator of DigitalCommons@University of Nebraska - Lincoln. 


\section{Authors}

Nicholas Miller, Arnaud Estoup, Stefan Toepfer, Denis Bourguet, Laurent Lapchin, Sylvie Derridj, Kyung

Seok Kim, Philippe Reynaud, Lorenzo Furlan, and Thomas Guillemaud 


\title{
Multiple Transatlantic Introductions of the Western Corn Rootworm
}

\author{
Nicholas Miller, ${ }^{1}$ Arnaud Estoup, ${ }^{2}$ Stefan Toepfer, ${ }^{3}$ \\ Denis Bourguet, ${ }^{2}$ Laurent Lapchin, ${ }^{1}$ Sylvie Derridj, ${ }^{4}$ \\ Kyung Seok Kim, ${ }^{5}$ Philippe Reynaud, ${ }^{6}$ \\ Lorenzo Furlan, ${ }^{7}$ Thomas Guillemaud ${ }^{1 *}$
}

Prevention of biological invasions, as opposed to remedial eradication of invasive species, represents the most cost-effective and perhaps only hope for stemming the current homogenization of the world's biota (1). Here we describe the introduction routes into Europe of the western corn rootworm (Diabrotica virgifera virgifera, WCR), the most destructive pest of corn in the United States. Armed with this knowledge, it will be possible to better gauge the prevention strategies that might be adopted.

WCR was first detected in Europe in the former Yugoslavia in 1992 and has since spread throughout much of central and southeastern (CSE) Europe (2). Outbreaks of WCR were subsequently detected in northeast Italy in 1998 (in Veneto), 2002 (in Pordenone), and 2003 (in Udine); in northwest Italy and Switzerland in 2000; near Paris, France, in 2002 and 2004; and in eastern France, Switzerland, Belgium, the United Kingdom, and the Netherlands in 2003 (2). Although the invasion history of WCR is well documented, the source populations of the Western European outbreaks remain unknown. Because of the sequence of outbreaks, CSE Europe was generally assumed to be the source of most, if not all, the Western European populations (3). However, in principle, each outbreak could have originated from North America, CSE Europe, or one of the other Western European foci.
To discriminate between these introduction scenarios, we analyzed the genetic variation of European and American WCR populations at eight microsatellite loci $(4,5)$. Simple genetic statistics gave useful but qualitative insights into the origin of most European outbreaks (5) (table $\mathrm{S} 1)$. We then used a model-based approximate Bayesian computation $(\mathrm{ABC})$ method relying on computer simulations $(5,6)$ to quantitatively compare the different introduction scenarios for the Western European WCR populations (Fig. 1).

Our results are clear-cut and unexpected. Two of the Western European populations analyzed did not originate from CSE Europe but directly from North America; this scenario was supported by Bayes factors $(B F)$ higher than $10^{5}$ and posterior weights $(P W)$ of $\sim 1$ for the northwestern Italy and Paris 2002 populations. Moreover, these introductions were independent from each other ( $B F \geq 159$ and $P W \geq 0.94$ ). According to our analysis, the northeastern Italy 2003 outbreak was the only one to originate from CSE Europe $(B F=183$ and $P W=0.94)$, and the eastern France population was derived from the Paris 2002 population $(B F=3.9$ and $P W=0.45)$. The only population with ambiguous origins was Paris 2004, which could have been derived either from North America $(B F=2.05$ and $P W=0.70)$ or from Paris $2002(P W=0.22)$. The presence of unsampled European populations acting as

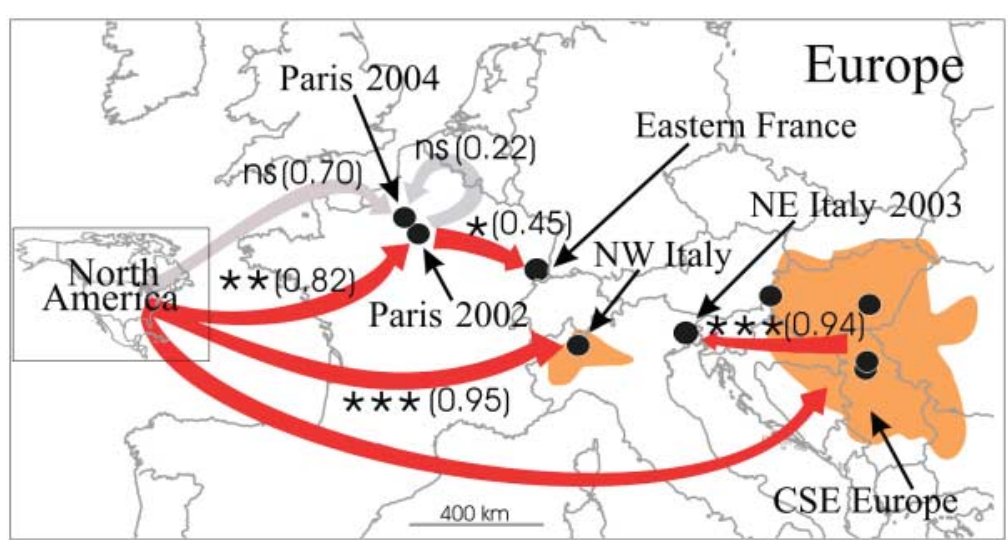

Fig. 1. The most likely scenarios of invasion into Europe by $W C R$, deduced from the $A B C$ analysis. For each European outbreak, a red arrow indicates its most likely origin; the $P W$ values of the introduction scenarios are in parentheses. Gray arrows represent unresolved scenarios. Large areas where WCR is present are shown in orange. $B F$ values supporting the most likely scenarios of 3.2 to 10 (substantial support), 10 to 100 (strong support), and >100 (decisive support) are indicated by one, two, or three asterisks, respectively; ns, not supported. alternative introduction sources for the three primary outbreaks (CSE Europe, northwestern Italy, and Paris 2002) could be ruled out. This was true whether the unsampled population was one of those detected in $2003\left(B F>10^{4}\right.$ and $P W \sim 1$ ) or a hypothetical population founded in the 1980s $(B F>3.6$ and $P W>0.68)$.

It has been widely assumed that the European WCR invasion was the result of a single unpredictable introduction. Our finding that there have been at least three independent transatlantic introductions of WCR suggests that incursions from North America are chronic. Prevention of future WCR invasions will require action against multiple invasion routes, which have apparently been used repeatedly and are potentially predictable. Our study also raises questions concerning the changing circumstances (such as adaptation by the insect or changes in control measures or transportation practices) that have permitted a sudden and recent burst of transatlantic introductions of WCR.

\section{References and Notes}

1. R. N. Mack et al., Ecol. Appl. 10, 689 (2000).

2. J. Kiss et al., in Western Corn Rootworm: Ecology and Management, S. Vidal, U. Kuhlmann, C. R. Edwards, Eds. (CABI, Wallingford, UK, 2005), pp. 29-39.

3. M. Enserink, Science 285, 1834 (1999).

4. K. S. Kim, T. W. Sappington, Mol. Ecol. Notes 5, 115 (2005).

5. Materials and methods are available as supporting material on Science Online.

6. M. A. Beaumont, W. Y. Zhang, D. J. Balding, Genetics 162, 2025 (2002).

7. We thank M. Beaumont, J. Shykoff, T. Lenormand, T. Sappington, P. David, and three anonymous reviewers for helpful comments and the Santé des Plantes et Environnement department of INRA and Direction Générale de l'Alimentation for funding.

Supporting Online Material www.sciencemag.org/cgi/content/full/310/5750/992/ DC1

Materials and Methods

Table S1

References and Notes

8 June 2005; accepted 4 October 2005 $10.1126 /$ science. 1115871

${ }^{1}$ Biologie des Populations en Interaction, Unité Mixte de Recherche (UMR) 1112 Institute National de la Recherche Agronomique (INRA)-Université de NiceSophia Antipolis, 400 Route des Chappes, 06903 Sophia Antipolis Cedex, France. ${ }^{2}$ Centre de Biologie et de Gestion des Populations, CS 30 016, 34988 Montferrier Cedex, France. ${ }^{3} \mathrm{CABI}$ Bioscience, Switzerland Centre Field Laboratories, c/o Plant Health Service, Rarosi ut 110, 6800 Hodmezovasarhely, Hungary. ${ }^{4}$ Physiologie de l'insecte-Signalisation et communication, UMR 1272 INRA, Route de St Cyr, 78026 Versailles, France. ${ }^{5}$ U.S. Department of Agriculture, Agricultural Research Service, Corn Insects and Crop Genetics Research Unit Genetics Laboratory, lowa State University, Ames, IA 50011, USA. '6aboratoire National de la Protection des Végétaux, 2 place Viala, 34060 Montpellier, France. ${ }^{7}$ Dipartimento di Agronomia Ambientale e Produzioni Vegetali, Agripolis, via Romea 16, 35020 Legnaro (Padova), Italy.

*To whom correspondence should be addressed. E-mail: guillem@antibes.inra.fr 


\section{Supporting Online Material: Materials and Methods}

The analyzed samples (Table S1) were genotyped using 7 microsatellite markers described previously (S1) and DVV-ET1 (for: 5'-ATGAAATGCCCGATGAAAAG-3' and rev: 5'-TTCCAACATAGTTGTCATCATC-3'). Genetic variation was summarized using several statistics: The mean number of alleles per locus and population, mean heterozygosity ( $S 2)$, mean ratio of the number of alleles over the range of allelic sizes expressed in base pairs (S3), between-population $F_{\mathrm{ST}}$ values (S4), and mean individual assignment likelihoods of individuals from population $i$ assigned into population $j\left(L_{i \rightarrow j}\right.$; (S5)).

The qualitatively deduced origin of each European outbreak is the sample for which $L_{\mathrm{i} \rightarrow \mathrm{j}}$ is maximised and the $F_{S T}$-value is among the smallest (Table S1). This approach remains qualitative because stochastic variation in $F_{S T}$ and $L_{\mathrm{i} \rightarrow \mathrm{j}}$ is not taken into account. Moreover, it assumes that all putative source populations were sampled which is not the case.

A quantitative Approximate Bayesian Computation method that accounts for stochastic variation in the summary statistics and does not assume that all source populations were sampled was used to estimate Bayes factors (BF (S6)) and posterior weights $(P W)$ of the favoured introduction scenarios. $B F$ and $P W$ combine prior and posterior historical and genetic information to provide evidence in favour of a given introduction scenario versus alternative scenarios. This method relies on simulating genetic data according to an introduction scenario and genetic and demographic parameters. For each introduction scenario the distribution of Euclidian distances between the summary statistics of actual and simulated genetic data is then computed from one million iterations. The extreme low end of the distribution (representing the simulations with parameter values that gave results closest to the observed data) is then used to estimate $B F$ and $P W(S 7, S 8)$. Note that $B F$ make pairwise comparisons of scenarios whereas $P W$ are computed considering all possible scenarios. We used a stochastic procedure specifically written to iteratively simulate genetic data using a coalescent framework (S9).

For each pair of European populations, three introduction scenarios were considered: 1) A serial introduction scenario in which an initial introduction occurred from North America into the first outbreak, and then from there into the second outbreak; 2) An American independent introduction scenario in which the two European outbreaks were founded by two independent introductions from North America; and 3) a European independent introduction scenario in which the two European outbreaks were independently founded by individuals originating from an unsampled European population, itself originating from North America. We assumed that this unsampled European population could be one of the unsampled outbreaks detected in 2003 (i.e. the UK, the Netherlands or Belgium). We also confirmed that our conclusions held if we considered an older undetected outbreak founded in the 1980s. If we had not considered the third scenario, and if two European outbreaks were founded from an unsampled European population, one could conclude that they were founded independently by two American introductions when in fact there was a single introduction from North America. 
Each outbreak was assumed to be founded by a small effective number of founders, $N_{f}$, originating from a source population. We also assumed that $N_{f}$ remained constant for a few generations (bottleneck duration) and then instantaneously reached a stable effective population size, $N_{s}$, that was the same for all populations. Because of the small population size soon after introduction, a time lag is likely to exist between the actual date of introduction and the date of first observation of a newly founded population. Each outbreak was thus characterized by (i) its geographic origin (North America or another European population), (ii) $N_{f}$, (iii) the duration of the bottleneck, $D B$ and (iv) the time lag, $T L$, between the actual introduction year and the first observation year.

Each possible introduction scenario was given the same prior weight, and the prior distributions chosen for the demographic and mutational parameters of our models were as follows. $N_{s}$ : $\log U$ niform[100; 100000] (5\% and 95\% quantiles of 141 and 7916); $N_{f}$ : $\log$ Uniform $[1 ; 100]$ (5\% and 95\% quantiles of 1 and 79). Generation time: one year (S10). $D B$ : Discrete Uniform[1; 5]. TL: Custom Discrete[1;DB] defined as follows: we assumed that the probability of observing WCR increases with the time since introduction, and we arbitrarily chose that the probability of observing the beetles $n$ years after the actual introduction year $\left(p_{n}\right)$ was such that $p_{n}=\frac{3}{2} p_{n-1}$; we also assumed that once at $N_{s}$, the WCR population was observable with a probability of 1 . Mean mutation rate $\bar{\mu}: \log U$ niform[10${ }^{4}$; $5 \times 10^{-3}$ ] (5\% and $95 \%$ quantiles of $1.2 \times 10^{-4}$ and $4.1 \times 10^{-3}$ ) (S11). Single locus mutation rates $\mu$ : $\operatorname{Gamma}(2 ; 2 / \bar{\mu})\left(5 \%\right.$ and $95 \%$ quantiles of $5.6 \times 10^{-5}$ and $\left.4.9 \times 10^{-3}\right)$. We used the generalised stepwise mutation model (S12), in which the change in the number of repeat units forms a geometric distribution with a variance $V g$ : $\operatorname{Exp}(0.36)(S 11)$ (5\% and 95\% quantiles of 0.02 and 1.08). 


\section{Table S1}

\begin{tabular}{lcccccc}
\hline & \multicolumn{7}{c}{ Outbreak } \\
\cline { 2 - 7 } $\begin{array}{l}\text { Putative } \\
\text { source }\end{array}$ & $\begin{array}{c}\text { CSE } \\
\text { Europe }\end{array}$ & NW Italy & NE Italy-2003 & Paris-2002 & Paris-2004 & $\begin{array}{c}\text { Eastern } \\
\text { France }\end{array}$ \\
\hline North America & $\mathbf{- 7 . 7 ( \mathbf { 0 . 0 8 } )}$ & $\mathbf{- 7 . 8 ( \mathbf { 0 . 0 8 } )}$ & $-8.3(0.22)$ & $\mathbf{- 8 . 3 ( \mathbf { 0 . 0 2 } )}$ & $\mathbf{- 8 . 2 ( \mathbf { 0 . 0 5 } )}$ & $\mathbf{- 8 . 2 ( \mathbf { 0 . 0 3 } )}$ \\
CSE Europe & - & $-13.7(0.20)$ & $\mathbf{- 4 . 7 ( \mathbf { 0 . 1 3 } )}$ & $-14.6(0.14)$ & $-12.1(0.15)$ & $-14.4(0.11)$ \\
NW Italy & -13.9 & - & $-15.0(0.40)$ & $-12.7(0.15)$ & $-11.3(0.14)$ & $-12.4(0.16)$ \\
NE Italy-2003 & -11.1 & -17.9 & - & $-21.3(0.38)$ & $-18.0(0.30)$ & $-19.5(0.36)$ \\
Paris-2002 & -9.4 & -10.1 & -11.2 & - & $-10.8(0.11)$ & $-\mathbf{- 8 . 9 ( 0 . 0 1 )}$ \\
Paris-2004 & -11.5 & -10.3 & -11.6 & -13.1 & - & $-14.0(0.14)$ \\
Eastern France & -9.2 & -11.0 & -10.1 & -9.3 & -9.9 & - \\
\hline Deduced origin & North & North & CSE Europe & North & North & North \\
& America & America & & America & America & America \\
& & & & & & or Paris-2002 \\
\hline
\end{tabular}

Most likely invasion scenarios of Europe by the western corn rootworm deduced from mean assignment log-likelihood of individuals from the European outbreaks (columns) to putative source populations (rows), and $F_{S T}$-values between pairs of populations (in parentheses). The deduced origin of each European outbreak is the sample for which the assignment likelihood is maximised and the $F_{S T \text {-value is }}$ among the smallest (values in bold). Studied outbreaks were those detected near Paris in $2002(n=9)$ and $2004(n=63)$, in North-Western Italy ( $n=40)$ and North-Eastern Italy in $2003(n=17)$, and in Eastern France $(n=7)$. The CSE European samples $(n=34-40)$ were genetically undifferentiated $(p>0.05)$ and were therefore pooled. The same was true for the samples collected from Iowa, Ohio and Illinois $(n=53-$ $61)$. 


\section{References}

S1. K. S. Kim, T. W. Sappington, Environ. Entomol. 34, 494 (2005).

S2. M. Nei, Molecular Evolutionary Genetics (Columbia University Press, New York, 1987)

S3. $\quad$ J. C. Garza, E. G. Williamson, Mol. Ecol. 10, 305 (2001).

S4. $\quad$ B. S. Weir, C. Cockerham, Evolution 38, 1358 (1984).

S5. $\quad$ B. Rannala, J. L. Mountain, Proc. Natl. Acad. Sci. U.S.A. 94, 9197 (1997).

S6. $\quad$ R. E. Kass, A. E. Raftery, J. Am. Stat. Assoc. 90, 773 (1995).

S7. $\quad$ M. A. Beaumont, W. Y. Zhang, D. J. Balding, Genetics 162, 2025 (2002).

S8. G. R. Terrell, D. W. Scott, Ann. Stat. 20, 1236 (1992).

S9. $\quad$ M. Norborg, in Handbook of Statistical Genetics D. J. Balding, M. Bishop, C. Cannings, Eds. (John Wiley, Baffins Lanes, 2001) pp. 179-212.

S10. S. Toepfer, U. Kuhlmann, in Western Corn Rootworm: Ecology and Management S. Vidal, U. Kuhlmann, C. R. Edwards, Eds. (Wallingford, 2005) pp. 95-120.

S11. L. Excoffier, A. Estoup, J.-M. Cornuet, Genetics 169, 1727 (2005).

S12. L. A. Zhivotovsky, M. W. Feldman, S. A. Grishechkin, Mol. Biol. Evol. 14, 926 (1997). 